\title{
Silica exposure, silicosis, and lung cancer: a necropsy study
}

\author{
P A Hessel, G K Sluis-Cremer, E Hnizdo
}

\begin{abstract}
Recent studies of the association between lung cancer and silicosis and silica dust have been inconclusive; some showing positive association and some showing none. The present study matched 231 cases of lung cancer with 318 controls by year of birth. Subjects were selected from the necropsy records of the National Centre for Occupational Health. Data on intensity and duration of exposure to silica dust were obtained from personnel records. Presence or absence of lung cancer and the presence and severity of silicosis of the parenchyma, pleura, and hilar glands were documented from necropsy reports. Smoking data were abstracted from records of routine examinations. No case-control differences were noted for any of the exposure indicators including cumulative dust exposure, total dusty shifts, weighted average intensity of exposure, total underground shifts, and shifts in high dust. Similarly, no association was found between lung cancer and the presence or severity of silicosis of any site. Stratified analyses showed neither significant nor suggestive trends when case-control comparisons for silicosis were examined by level of dust exposure or smoking. Reasons for disparity between these results and those of some other studies may include concomitant exposures to radon daughters, asbestos, diesel emissions, and cigarette smoking; idiosyncracies of the compensation process; and the possibility of a threshold in the relation(s).
\end{abstract}

The possibility of an association between occupational exposure to silica and a raised risk of lung cancer has been explored recently using various study designs and worker populations. Similarly, the possibility of an association between silicosis and lung cancer has been investigated. Despite this level

Epidemiology Research Unit, PO Box 4584, Johannesburg 2000, South Africa

P A Hessel, G K Sluis-Cremer, E Hnizdo of interest, the questions of the carcinogenicity of silica and an association between silicosis and lung cancer remain unanswered.

A recent International Agency for Research on Cancer monograph evaluated the existing experimental and human data and concluded that there was sufficient evidence for the carcinogenicity of crystalline silica in experimental animals and that there was limited evidence for the carcinogenicity of crystalline silica in man. ${ }^{1}$ There was inadequate evidence for the carcinogenicity of amorphous silica in either animals or man. Limited evidence in man implies that a causal interpretation is credible but that alternative explanations, such as chance, bias, or confounding, could not adequately be excluded. McDonald, commenting on the interpretation of the human studies stated that "the epidemiological findings are not consistent, risk estimates are generally low, exposure response has not been studied, and the possibilities for confounding by other carcinogens, including tobacco, are many."

The present case-control study follows a previous study in which no association was found between lung cancer and either silicosis or exposure to silica dust in South African gold miners identified from the records of their pension fund. ${ }^{3}$ The present study extends that work, identifying cases and controls from the computerised records of necropsies performed on white gold miners at the National Centre for Occupational Health in Johannesburg. Both the role of silica as a lung carcinogen and the association between silicosis and lung cancer are explored.

\section{Materials and methods}

Current legislation in South Africa states that any attending physician who knows or suspects that his dead patient was a miner is obliged to remove the cardiorespiratory organs and send them to the Medical Bureau for Occupational Diseases if permission is granted by next of kin. Pathologists at the National Centre for Occupational Health examine the organs. Although adherence to the law is not complete, estimates for the gold mining industry indicate that postmortem examinations are performed on approximately $86 \%$ of white gold miners. ${ }^{3}$ Since 1975 the results of these examinations have been computerised using the pathology automation 
system. ${ }^{4}$ More than 3000 necropsies a year have been recorded in this way.

All white miners exposed to silica-that is, those with at least $80 \%$ of their mining employment in silica containing mines, usually gold mines, with carcinoma found in the lungs at necropsies-were selected as potential cases $(n=571)$. An equal number of white miners who had been exposed to silica was selected as potential controls, stratified by age at death according to the age distribution of the cases. Miners who died between January 1979 and October 1983 (the period covered by the previous study $^{3}$ ) were excluded to ensure independence of the results of the two studies.

The medical files of the Medical Bureau for Occupational Diseases which included the records of periodical (usually annual) examinations, specialist examinations for the purpose of assessing eligibility for compensation, detailed work histories, and the results of the necropsies were examined. Cases were excluded if it was found that their carcinomas were not bronchogenic $(n=134)$. Most were stated specifically to have been metastatic; however, those listed as having a primary tumour of unknown origin were also excluded. Thirteen cases and 35 controls were excluded because no smoking information was available in the medical files. Miners who had worked fewer than 1000 shifts (about four years) in siliceous dust were excluded ( 48 cases, 63 controls) as were those with more than $20 \%$ of their service in non-silica containing mines ( 15 cases, nine controls). Miners who worked for more than one year in an asbestos mine (four cases, three controls) or as boilermakers (16 cases, 11 controls) were also excluded. Medical Bureau for Occupational Diseases files could not be found for 11 cases and 17 controls and the files of two cases and one control contained no information. One case and one control were found to have died outside the period of interest and four miners originally selected as controls were found to have had bronchogenic carcinomas that had been resected in life and therefore had not been documented at necropsy. These four were reclassified as cases.

The remaining cases and controls were matched randomly by age at death. Nine controls could not be matched and were excluded. The remaining study group comprised 231 cases and 318 controls; each case having at least one control and none having more than two.

Cumulative exposure to silica dust was calculated by multiplying the number of shifts worked in a dusty atmosphere by a weighting factor proportional to the dust concentration of each occupation. ${ }^{5}$ The intensity of exposure in different occupations (weighted by the number of shifts at each level of intensity) was calculated. Occupations were coded as non-dusty, low, moderate, or high dust and weighted $0,3,6$, and 12 , respectively. Shifts at high dust were also considered separately. The intensity of exposure was derived from the work of Beadle who performed full shift estimates of exposure in a random sample of 650 men in different occupations in 20 Witwatersrand gold mines in $1966 .^{5}$

The assessment of silicosis was obtained from the necropsy report. The diagnosis of silicosis at necropsy is a medicolegal diagnosis and represents the opinion of the pathologist who has access to the occupational history of the worker at the time of the postmortem examination. The diagnosis of slight silicosis may be made on the basis of a single nodule in the parenchyma. The assessment of silicosis at necropsy was made with the knowledge of whether the miners had lung cancer or not. This was unlikely to cause bias as the necropsies were conducted before the start of the study and the pathologists were not aware of the objectives of the study. Silicosis of the parenchyma and pleura was graded by the pathologists as none, minimal, slight, moderate, or pronounced. Silicosis of the hilar glands was graded as none, slight, moderate, or pronounced.

Cases and controls were classified into five smoking categories representing their smoking status at death (or as near to death as possible) based on information in the Medical Bureau for Occupational Diseases files as: (1) lifelong non-smokers; (2) light ex-smokers, smoking 15 or fewer cigarettes or equivalents a day assessed 10 years before death or two or more years before quitting, whichever was earlier and having quit at least two years before death; (3) heavy ex-smokers, as for light ex-smokers but smoking 16 or more cigarettes or equivalents a day; (4) light current smokers, smoking 15 or fewer cigarettes or equivalents a day assessed 10 years before death and not an ex-smoker, and (5) heavy current smokers, as for light current smokers but smoking 16 or more cigarettes or equivalents a day.

In addition, the number of cigarettes or equivalents smoked a day at five, 10,15 , and 20 years before death (within two years) were recorded when available. One gram of pipe tobacco was considered equivalent to one cigarette and one cigar equivalent to five cigarettes.

Univariate comparisons were performed using the $t$ test for continuous variables and the chi-squared test, and the chi-squared test for trend for categorical variables. Multivariate comparisons of silicosis and lung cancer were first performed by stratification, looking for trends in the odds ratios, and by using conditional multiple logistic regression, controlling for smoking, cumulative exposure to silica dust, and age. Odds ratios for lung cancer and silicosis were calculated for each quartile of cumulative dust exposure. These odds ratios were tested for equality using the Breslow-Day test for homogeneity. Mantel-Haenszel summary odds ratios were also calculated with $95 \%$ confidence intervals. 
Table 1 Description of the study population

\begin{tabular}{|c|c|c|c|c|c|c|c|}
\hline & \multicolumn{3}{|c|}{ Cases } & \multicolumn{3}{|c|}{ Controls } & \multirow[b]{2}{*}{$p$} \\
\hline & No & Mean & $S D$ & No & Mean & $S D$ & \\
\hline $\begin{array}{l}\text { Total subjects } \\
\text { Age at death } \\
\text { Average cig/day: }\end{array}$ & $\begin{array}{l}231 \\
231\end{array}$ & $65 \cdot 6$ & $7 \cdot 8$ & $\begin{array}{l}318 \\
318\end{array}$ & $65 \cdot 1$ & $8 \cdot 0$ & 0.44 \\
\hline $\begin{array}{l}5 \text { years to death } \\
10 \text { years to death } \\
15 \text { years to death } \\
20 \text { years to death }\end{array}$ & $\begin{array}{l}202 \\
210 \\
208 \\
185\end{array}$ & $\begin{array}{l}12 \cdot 4 \\
14 \cdot 7 \\
17 \cdot 7 \\
18 \cdot 7\end{array}$ & $\begin{array}{l}10.8 \\
10.9 \\
11.0 \\
11.6\end{array}$ & $\begin{array}{l}278 \\
291 \\
288 \\
259\end{array}$ & $\begin{array}{r}8 \cdot 2 \\
11 \cdot 3 \\
13 \cdot 4 \\
13 \cdot 7\end{array}$ & $\begin{array}{l}10 \cdot 0 \\
10 \cdot 8 \\
12 \cdot 5 \\
12 \cdot 4\end{array}$ & $\begin{array}{l}<0.0001 \\
<0.0004 \\
<0.0001 \\
<0.0001\end{array}$ \\
\hline $\begin{array}{l}\text { Dust exposure: } \\
\text { CDE } \\
\text { Intensity } \\
\text { Total dusty shifts } \\
\text { Shifts in high dust } \\
\text { Shifts underground }\end{array}$ & $\begin{array}{l}231 \\
231 \\
231 \\
231 \\
231\end{array}$ & $\begin{array}{c}35377 \\
5 \cdot 29 \\
6572 \\
539 \\
6206\end{array}$ & $\begin{array}{c}18937 \\
1 \cdot 70 \\
2434 \\
1239 \\
2739\end{array}$ & $\begin{array}{l}318 \\
318 \\
318 \\
318 \\
318\end{array}$ & $\begin{array}{c}35639 \\
5 \cdot 24 \\
6713 \\
480 \\
6221\end{array}$ & $\begin{array}{c}19088 \\
1 \cdot 70 \\
2503 \\
1142 \\
2765\end{array}$ & $\begin{array}{l}0.874 \\
0.744 \\
0.510 \\
0.565 \\
0.951\end{array}$ \\
\hline
\end{tabular}

Comparisons made using $t$ test.

$\mathrm{CDE}=$ Cumulative dust exposure: see text for derivation.

Ranges for dust exposure:

CDE:(3093-101907), intensity: (1.98-10.70), total dusty shifts:(1034-14 094), shifts in high dust:(0-9029), shifts underground: (0-13 427).

\section{Results}

Cases and controls were comparable for age at death with cases being 65.6 and controls $65 \cdot 1$ years old. Table 1 shows some exposure characteristics of the cases and controls. Not surprisingly the cases smoked more than the controls. Each measure of silica dust exposure, however, indicated no case-control difference. Cases and controls were comparable for cumulative silica dust exposure, weighted average intensity of exposure, total shifts worked in dust, total underground shifts, and the number of shifts in high dust (all high dust shifts would have been worked underground). The figure for average intensity of exposure corresponds to a dust level of about $0.2 \mathrm{mg} / \mathrm{m}^{3}$.

The data in table 2 indicate that there was no association between lung cancer and the presence of silicosis of the parenchyma, pleura, or hilar glands. These comparisons were adjusted, using conditional

Table 2 Unmatched comparison of cases and controls for presence of silicosis of the parenchyma, pleura, and hilarglands

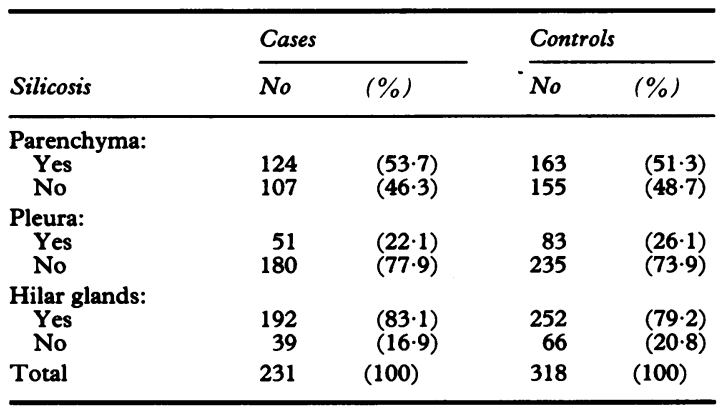

For silicosis of the parenchyma: $O R=1 \cdot 10,95 \% C I=(0 \cdot 79$ 0.60 ).

For silicosis of the pleura: $O R=0.80,95 \% \mathrm{CI}=(0.54-1 \cdot 20)$.

For silicosis of the hilar glands: $O R=1.29,95 \% \mathrm{CI}=(0 \cdot 83-2.00)$. logistic regression, for age, smoking category, and cumulative dust exposure, no significant changes in the odds ratios being noted. Comparison of cases and controls by severity of silicosis of each of these sites showed no significant associations and no suggestive trends were noted (table 3 ).

The presence of silicosis was compared for cases and controls by quartile of dust exposure. No trend in the odds ratios was apparent for silicosis of the parenchyma (table 4) or pleura (table 5); however, the odds ratios decreased with increasing dust exposure for silicosis of the hilar glands (table 6). None of the Mantel-Haenszel summary odds ratios differed significantly from one and the odds ratios for each site of silicosis were not inhomogeneous.

Table 3 Unmatched comparison of cases and controls for the degree of silicosis of the parenchyma, pleura, and hilar glands

\begin{tabular}{|c|c|c|c|c|}
\hline \multirow[b]{2}{*}{ Silicosis } & \multicolumn{2}{|c|}{ Cases } & \multicolumn{2}{|c|}{ Controls } \\
\hline & No & $(\%)$ & No & $(\%)$ \\
\hline $\begin{array}{l}\text { Parenchyma: } \\
\text { None } \\
\text { Minimal } \\
\text { Slight } \\
\text { Moderate } \\
\text { Pronounced }\end{array}$ & $\begin{array}{r}107 \\
56 \\
40 \\
24 \\
4\end{array}$ & $\begin{array}{l}(46 \cdot 3) \\
(24 \cdot 3) \\
(17 \cdot 3) \\
(10 \cdot 4) \\
(1 \cdot 7)\end{array}$ & $\begin{array}{r}155 \\
79 \\
43 \\
30 \\
11\end{array}$ & $\begin{array}{r}(48.7) \\
(24.9) \\
(13.5) \\
(9.4) \\
(3.5)\end{array}$ \\
\hline $\begin{array}{l}\text { Pleural: } \\
\text { None } \\
\text { Minimal } \\
\text { Slight } \\
\text { Moderate } \\
\text { Pronounced }\end{array}$ & $\begin{array}{r}180 \\
33 \\
15 \\
3 \\
0\end{array}$ & $\begin{array}{r}(77 \cdot 9) \\
(14 \cdot 3) \\
(6 \cdot 5) \\
(1 \cdot 3) \\
(0 \cdot 0)\end{array}$ & $\begin{array}{r}235 \\
49 \\
18 \\
15 \\
1\end{array}$ & $\begin{array}{r}(73.9) \\
(15.4) \\
(5 \cdot 7) \\
(4 \cdot 7) \\
(0.3)\end{array}$ \\
\hline $\begin{array}{l}\text { Hilar glands: } \\
\text { None } \\
\text { Slight } \\
\text { Moderate } \\
\text { Pronounced }\end{array}$ & $\begin{array}{r}39 \\
35 \\
106 \\
51\end{array}$ & $\begin{array}{l}(16 \cdot 9) \\
(15 \cdot 2) \\
(45 \cdot 9) \\
(22 \cdot 1)\end{array}$ & $\begin{array}{r}66 \\
35 \\
146 \\
71\end{array}$ & $\begin{array}{l}(20.8) \\
(11.0) \\
(45.9) \\
(22.3)\end{array}$ \\
\hline Total & 231 & $(100)$ & 318 & $(100)$ \\
\hline
\end{tabular}

For silicosis of the parenchyma: $\chi_{\text {trend }}^{2}=0.09, \mathrm{df}=1, \mathrm{p}=0.76$. For silicosis of the pleura: $\chi_{\text {trend }}^{2}=2 \cdot 8, \mathrm{df}=1, \mathrm{p}=0.09$.

For silicosis of the hilar glands: $\chi_{\text {trend }}^{2}=0.145, \mathrm{df}=1, \mathrm{p}=0.70$. 
Table 4 Comparison of cases and controls for presence of silicosis of the parenchyma by quartile of cumulative dust exposure (CDE)

\begin{tabular}{|c|c|c|c|c|c|c|}
\hline \multirow{2}{*}{$\begin{array}{l}C D E \\
\text { quartile }\end{array}$} & \multirow[b]{2}{*}{ Silicosis } & \multicolumn{2}{|c|}{ Cases } & \multicolumn{2}{|c|}{ Controls } & \multirow[b]{2}{*}{$O R$} \\
\hline & & No & $(\%)$ & No & $(\%)$ & \\
\hline 1 & $\begin{array}{l}\text { Yes } \\
\text { No }\end{array}$ & $\begin{array}{l}17 \\
40\end{array}$ & $\begin{array}{l}(29 \cdot 8) \\
(70 \cdot 2)\end{array}$ & $\begin{array}{l}15 \\
65\end{array}$ & $\begin{array}{l}(18 \cdot 8) \\
(81 \cdot 3)\end{array}$ & 1.84 \\
\hline 2 & $\begin{array}{l}\text { Yes } \\
\text { No }\end{array}$ & $\begin{array}{l}26 \\
31\end{array}$ & $\begin{array}{l}(45 \cdot 6) \\
(54 \cdot 4)\end{array}$ & $\begin{array}{l}41 \\
39\end{array}$ & $\begin{array}{l}(51 \cdot 3) \\
(48 \cdot 8)\end{array}$ & 0.80 \\
\hline 3 & $\begin{array}{l}\text { Yes } \\
\text { No }\end{array}$ & $\begin{array}{l}42 \\
19\end{array}$ & $\begin{array}{l}(68 \cdot 9) \\
(31 \cdot 2)\end{array}$ & $\begin{array}{l}54 \\
23\end{array}$ & $\begin{array}{l}(70 \cdot 1) \\
(29 \cdot 9)\end{array}$ & 0.94 \\
\hline 4 & $\begin{array}{l}\text { Yes } \\
\text { No }\end{array}$ & $\begin{array}{l}39 \\
17\end{array}$ & $\begin{array}{l}(69 \cdot 6) \\
(30 \cdot 4)\end{array}$ & $\begin{array}{l}53 \\
28\end{array}$ & $\begin{array}{l}(65 \cdot 4) \\
(34 \cdot 6)\end{array}$ & $1 \cdot 21$ \\
\hline Total & & 231 & $(100)$ & 318 & $(100)$ & \\
\hline
\end{tabular}

$\mathrm{OR}_{\mathrm{M}-\mathrm{H}}=1 \cdot 1,95 \% \mathrm{CI}=(0 \cdot 77-1 \cdot 58)$.

$x^{2}=2 \cdot 72, \mathrm{df}=3, \mathrm{p}>0.20$

Quartiles were determined by dividing the distribution of cumulative dust exposure (for cases and controls combined) in quarters. The first quartile represents the lowest quarter of the observations.

The association between silicosis and lung cancer was also examined according to the number of cigarettes smoked 10 years before death (table 7). No trends were apparent and the summary odds ratios did not significantly differ from one.

\section{Discussion}

The data presented above indicate no association between lung cancer and either silica dust exposure or silicosis. Several characteristics of the study should be considered in evaluating these results.

(1) Though the necropsy rate among white South African gold miners is approximately $86 \%,{ }^{3}$ the next of kin of miners who have been fully compensated in life (implying at least $40 \%$ disability) cannot benefit financially as a result of the necropsy findings. Workers fully compensated in life are, therefore, underrepresented (but certainly not unrepresented) in the necropsied population. Silicosis is not uncommonly found in fully compensated workers; however,

Table 5 Comparison of cases and controls for presence of silicosis of the pleura by quartile of cumulative dust exposure ( $C D E$ )

\begin{tabular}{|c|c|c|c|c|c|c|}
\hline \multirow{2}{*}{$\begin{array}{l}C D E \\
\text { quartile }\end{array}$} & \multirow[b]{2}{*}{ Silicosis } & \multicolumn{2}{|c|}{ Cases } & \multicolumn{2}{|c|}{ Controls } & \multirow[b]{2}{*}{$O R$} \\
\hline & & No & $(\%)$ & No & $(\%)$ & \\
\hline 1 & $\begin{array}{l}\text { Yes } \\
\text { No }\end{array}$ & $\begin{array}{r}4 \\
53\end{array}$ & $\begin{array}{r}(7 \cdot 0) \\
(93 \cdot 0)\end{array}$ & $\begin{array}{l}11 \\
69\end{array}$ & $\begin{array}{l}(13 \cdot 8) \\
(86 \cdot 3)\end{array}$ & 0.47 \\
\hline 2 & $\begin{array}{l}\text { Yes } \\
\text { No }\end{array}$ & $\begin{array}{r}9 \\
48\end{array}$ & $\begin{array}{l}(15 \cdot 8) \\
(84 \cdot 2)\end{array}$ & $\begin{array}{l}18 \\
62\end{array}$ & $\begin{array}{l}(22 \cdot 5) \\
(77 \cdot 5)\end{array}$ & 0.65 \\
\hline 3 & $\begin{array}{l}\text { Yes } \\
\text { No }\end{array}$ & $\begin{array}{l}22 \\
39\end{array}$ & $\begin{array}{l}(36 \cdot 1) \\
(63 \cdot 9)\end{array}$ & $\begin{array}{l}21 \\
56\end{array}$ & $\begin{array}{l}(27 \cdot 3) \\
(72 \cdot 7)\end{array}$ & 1.50 \\
\hline 4 & $\begin{array}{l}\text { Yes } \\
\text { No }\end{array}$ & $\begin{array}{l}16 \\
40\end{array}$ & $\begin{array}{l}(28 \cdot 6) \\
(71 \cdot 4)\end{array}$ & $\begin{array}{l}33 \\
48\end{array}$ & $\begin{array}{l}(40 \cdot 7) \\
(59 \cdot 3)\end{array}$ & 0.58 \\
\hline Total & & 231 & $(100)$ & 318 & $(100)$ & \\
\hline
\end{tabular}

$\mathrm{OR}_{\mathrm{M}-\mathrm{H}}=0 \cdot 79,95 \% \mathrm{CI}=(0 \cdot 52-1 \cdot 19)$.

$\chi_{\mathrm{B}-\mathrm{D}}^{2}=4 \cdot 67, \mathrm{df}=3, \mathrm{p}=0.20$.

Quartiles: see table 4.
Table 6 Comparison of cases and controls for presence of silicosis of the hilar glands by quartile of cumulative dust exposure (CDE)

\begin{tabular}{|c|c|c|c|c|c|c|}
\hline \multirow{2}{*}{$\begin{array}{l}C D E \\
\text { quartile }\end{array}$} & \multirow[b]{2}{*}{ Silicosis } & \multicolumn{2}{|c|}{ Cases } & \multicolumn{2}{|c|}{ Controls } & \multirow[b]{2}{*}{$O R$} \\
\hline & & No & $(\%)$ & No & $(\%)$ & \\
\hline 1 & $\begin{array}{l}\text { Yes } \\
\text { No }\end{array}$ & $\begin{array}{l}38 \\
19\end{array}$ & $\begin{array}{l}(66 \cdot 8) \\
(33 \cdot 3)\end{array}$ & $\begin{array}{l}44 \\
36\end{array}$ & $\begin{array}{l}(55.0) \\
(45.0)\end{array}$ & 1.64 \\
\hline 2 & $\begin{array}{l}\text { Yes } \\
\text { No }\end{array}$ & $\begin{array}{r}49 \\
8\end{array}$ & $\begin{array}{l}(86 \cdot 0) \\
(14 \cdot 0)\end{array}$ & $\begin{array}{l}64 \\
16\end{array}$ & $\begin{array}{l}(80.0) \\
(20.0)\end{array}$ & 1.53 \\
\hline 3 & $\begin{array}{l}\text { Yes } \\
\text { No }\end{array}$ & $\begin{array}{r}54 \\
7\end{array}$ & $\begin{array}{l}(88.5) \\
(11.5)\end{array}$ & $\begin{array}{r}68 \\
9\end{array}$ & $\begin{array}{l}(88 \cdot 3) \\
(11 \cdot 7)\end{array}$ & 1.02 \\
\hline 4 & $\begin{array}{l}\text { Yes } \\
\text { No }\end{array}$ & $\begin{array}{r}51 \\
5\end{array}$ & $\begin{array}{r}(91 \cdot 1) \\
(8.9)\end{array}$ & $\begin{array}{r}76 \\
5\end{array}$ & $\begin{array}{r}(93.8) \\
(6.2)\end{array}$ & 0.67 \\
\hline Total & & 231 & $(100)$ & 318 & $(100)$ & \\
\hline
\end{tabular}

$\mathrm{OR}_{\mathrm{M}-\mathrm{H}}=1 \cdot 31,95 \% \mathrm{CI}=(0 \cdot 83-2 \cdot 08)$.

$\chi^{2}-\mathrm{D}=1 \cdot 78, \mathrm{df}=3, \mathrm{p}>0 \cdot 20$.

Quartiles: see table 4.

much of the disability is thought to result from smoking. In the absence of silicosis 10-15 years of dusty work is usually required before compensation is considered. As a result, the sampling frame probably underrepresents gold miners who have been significantly disabled in life, owing in part to cigarette smoking but usually with appreciable exposure to silica. Because cases were selected on the basis of having lung cancer at necropsy and not on the basis of smoking, it is unlikely that this affected the results. In addition, the results obtained in this study are comparable with those reported in our previous study which used the same workforce but in which the subjects were identified through pension fund records. ${ }^{3}$ That sampling frame obviated any problems associated with underrepresentation of fully compensated workers which might have occurred among the cases and controls in this study.

(2) The method of selection of cases and controls resulted in the elimination from the control group of subjects with metastatic lung cancer. Subjects with any cancer of the lung were selected initially as potential controls and those with metastatic lung cancers were then excluded. Cancers other than lung were, therefore, underrepresented among controls. If these cancers were related to silica exposure or silicosis the odds ratios calculated would have been

Table 7 Unmatched odds ratios for the comparison of lung cancer and silicosis by number of cigarettes a day reported 10 years before death

\begin{tabular}{llll}
\hline \multirow{4}{*}{ Cigarettes a day } & \multicolumn{3}{l}{ Silicosis } \\
\cline { 2 - 4 } & Hilar glands & Parenchyma & Pleura \\
\hline 0 & 1.12 & 1.62 & 1.37 \\
$1-10$ & 0.44 & 0.40 & 0.98 \\
$11-20$ & 0.61 & 0.84 & 0.92 \\
$\geqslant 21$ & 0.75 & 0.88 & 1.17 \\
$\mathrm{M}-\mathrm{H}^{\star}$ & 0.68 & 0.81 & 1.08 \\
$95 \% \mathrm{CI}$ & $0.40-1.14$ & $0.55-1.21$ & $0.60-1.96$ \\
\hline
\end{tabular}

^Mantel-Haenszel summary odds ratio. 
overestimates of the true values. Neither silica nor silicosis have been linked to other cancers. Coronary heart disease, which may have been slightly overrepresented among the controls (owing to the absence of lung cancers and certain other metastatic lung cancers), had not been shown to be associated with silica exposure or silicosis in this population. ${ }^{6}$

(3) The use of dead controls is only valid if the causes of death of the controls are not related to the exposure under study. Causes of death were reviewed for all subjects and analyses were repeated, excluding controls and cases whose cause of death was listed as pneumoconiosis (one case, one control), tuberculosis (10 cases, six controls), nephritis (three cases, two controls), or obstructive airways disease. No changes in the results were noted.

(4) The possibility that miners who had been certified for silicosis in life might change their smoking habits after certification (specifically, cut down) was considered. Changes in smoking habits were determined for those who were certified either for silicosis or obstructive airways disease between five and 20 years before death; the period for which smoking data were available. Changes in smoking habits during the comparable period for those who were not certified in life showed that those who were certified for silicosis were less likely to decrease their smoking after certification (33\% decreased) than those certified for obstructive airways disease $(48 \%$ decreased), and were about as likely as those not certified in life (37\% decreased) to cut down.

(5) The lack of an association between exposure to silica dust and lung cancer shown in this study is consistent with most recently published reports. Nevertheless, the possibility that a threshold may exist for exposure to silica and risk of lung cancer should be considered. The data presented in several of the reported mortality studies indicate that exposure levels were probably high in some studies. Twenty four per cent of the deaths among controls in the population based study of Forastiere et al were attributed to silicosis. ${ }^{7}$ Similarly, Zambon et al reported that 236 of $878(27 \%)$ deaths in their study were due to silicosis with a further $175(20 \%)$ attributed to tuberculosilicosis-that is, nearly half the deaths reported were associated with occupational exposure to silica. ${ }^{8}$ On the other hand, in a recent mortality study of 3971 white South African gold miners neither silicosis nor tuberculosis could be considered the underlying cause of death in any worker when all available information including routine and specialist examinations in life (which included radiographs and lung function tests), postmortem examinations, death certificates, and hospital records was considered. ${ }^{6}$ Mean exposure was $0.2 \mathrm{mg} / \mathrm{m}^{3}$ of quartz in that study with a range from 0.1 to $0.8 \mathrm{mg} / \mathrm{m}^{3}$. In the present study the cause of death was based on the necropsy results and the death certificate. Pneumoconiosis was considered to be the cause of death for only one subject (a control) and tuberculosis the cause of death for four cases $(1.7 \%)$ and six controls $(1.9 \%)$. Possibly the dust concentrations in South African gold mines during the past 20 to 30 years have been so low that an exposure disease relation cannot be found.

(6) The possibility was considered that the entry criterion of at least 1000 dusty shifts, or employment practices and exposure characteristics, or all these, in the South African gold mines might have resulted in such limited variability in the exposure measures that an effect could not be seen. The standard deviations of the exposure measures listed in table 1 and the ranges noted in the footnote indicate a fairly wide spread of values for each exposure measure.

Most studies exploring the association between silicosis and lung cancer have shown positive associations, whereas this study and its predecessor ${ }^{3}$ showed no such association. Possible explanations for such a difference have been suggested by Heppleston," Archer et $a l,{ }^{10}$ and $\mathrm{McD}$ Donald, ${ }^{2}$ and include a lack of information on smoking and concomitant exposures to radon daughters and polycyclic aromatic hydrocarbons. It is worth while to explore these and other factors.

(1) Few data exist to evaluate the possible association between silicosis and smoking. An analysis of two cross sectional studies in white South African gold miners produced odds ratios of 1.5 and 1.7 for ever versus never smoking and the presence of radiological silicosis (unpublished data). Studies designed specifically to explore this association and including information on whether smoking and silica exposure were simultaneous should be undertaken. If such an association exists the results of follow up studies of silicotic subjects could be confounded seriously.

(2) Another possible confounder to be considered is asbestos. A recent study by Davies $e t$ al presented 19 mesotheliomas among South African gold miners who had no documented employment in the mining, milling, or processing of asbestos. ${ }^{11}$ Five were boilermakers, three fitters, and three electricians. In all, 15 of these 19 had evidence of possible exposure to asbestos, usually as artisans. In the present study 20 of what would have been 251 otherwise eligible cases $(8.0 \%)$ and 14 of what would have been 332 otherwise eligible controls $(4.5 \%, O R=1.97)$ were excluded because of a history of working in asbestos mines (four cases, and three controls) or as boilermakers (16 cases, 11 controls). We are planning to compare fibre levels in samples of lung tissue from cases and controls in the previous study ${ }^{3}$ to assess the possible role of asbestos in the aetiology of lung cancer in South African gold miners. Investigators without access to necropsy material might explore occupational histories in depth to search for sources 
of asbestos exposure, especially in case-control studies.

(3) The surveillance systems operating in many dusty industries enhance the likelihood of detecting cancers that might otherwise not be detected and bringing workers under intensive medical treatment which might minimise their chance of dying from another cause in the interim. Given the usual eventual outcome of lung cancer, this is probably not a major problem as most cancers would be recognised before death. In our previous study, however, several potential controls who had no indication of lung cancer on their death certificates were found to have had bronchogenic carcinomas when the results of their necropsies were reviewed. ${ }^{3}$ It is not known whether these were carcinomas that were not diagnosed in life or errors in completing the death certificates.

(4) Most follow up studies of silicotic subjects are based on compensation records. Compensation is usually based on disability as well as a radiological diagnosis of silicosis. These diagnoses of silicosis are often not made blindly but rather (as is appropriate in the medicolegal setting) with full knowledge and often because of the occupational history. Other factors such as socioeconomic circumstances may enter into these decisions. Importantly, disability must often be shown before compensation is awarded. Whereas exposure to silica has been shown to have a deleterious effect on lung function, ${ }^{12}$ currently available information indicates that simple silicosis per se does not have an effect [F J Wiles personal communication]. It is thought by many of those concerned in the awarding of compensation in South Africa that the disability documented in silicotic subjects and other miners exposed to silica results more from cigarette smoking than from silicosis. If this is general, compensated silicotic subjects in other countries may be those miners and other dust exposed workers who have been heavy smokers and hence are at higher risk for developing lung cancer. Considering this, and the possibility of an aetiological association between silicosis and smoking, it becomes apparent that smoking may seriously confound studies of silicotic subjects either directly or indirectly.

Future studies of silica, silicosis, and lung cancer should include individual smoking data that are as specific as possible; attempt to identify likely or possible exposures to asbestos, polycyclic aromatic hydrocarbons, and other potentially confounding exposures; quantify exposures to silica as accurately as possible; and use sensitive measures of the presence of silicosis, preferably postmortem evidence.

In addition to these studies, an attempt should be made to determine whether an association exists between silicosis and smoking. Where postmortem material is available, an effort should be made to compare fibre levels among cases of lung cancer without obvious (based on job titles) exposure to asbestos. The measurement of the effects of radiation exposures in these studies is usually difficult owing to sparse or absent historical data on exposures. These investigations should, however, be attempted.

It is unlikely that any single bias or error can account for reported discrepancies. Possibly, however, several of these sources of bias could be operating simultaneously to produce apparent associations. At present, viewing the growing body of publications, it is not yet possible to state with assurance that there is or is not an association between lung cancer and either silicosis or silica dust. What is clear is that future studies must concern themselves with the issues raised above if any progress is to be made in resolving this important issue.

Requests for reprints to: Dr P A Hessel, Department of Health Services Administration and Community Medicine, 13-103 Clinical Sciences Bldg, University of Alberta, Edmonton, Alberta, Canada T6G 2G3.

1 International Agency for Research on Cancer. Monographs on the evaluation of the carcinogenic risk of chemicals to humans. Vol 42. Silica and some silicates. Lyon: IARC, 1987.

$2 \mathrm{McDonald}$ JC. Silica, silicosis, and lung cancer. Br J Ind Med 1989;46:289-91.

3 Hessel PA, Sluis-Cremer GK, Hnizdo E. Case-control study of silicosis, silica exposure and lung cancer in white South African gold miners. Am J Ind Med 1986;20:57-62.

4 Hessel PA, Davies JCA, Goldstein B, Webster I, Hnizdo E, Landau S. Pathological findings in mineworkers. I: Description of the PATHAUT data base. Am J Ind Med 1987;12: 71-80.

5 Beadle DG, Harris E, Sluis-Cremer GK. The relationship between the amount of dust breathed and the incidence of silicosis. In: Shapiro HA, ed. Pneumoconiosis, proceedings of the international conference, Johannesburg, 1969. London: Oxford University Press, 1970:473-77.

6 Wyndham $\mathrm{CH}$, Bezuidenhout BN, Greenacre MJ, SluisCremer GK. Mortality of middle aged white South African gold miners. Br J Ind Med 1986;43:677-84.

7 Forastiere F, Lagorio S, Michelozzi P, et al. Silica, silicosis and lung cancer among ceramic workers: a case-referent study. $\mathbf{A m}$ $J$ Ind Med 1986;10:363-70.

8 Zambon P, Simonato L, Mastrangelo G, Winkelmann R, Saia B, Crepet M. Mortality of workers compensated for silicosis during the period 1959-1963 in the Veneto region of Italy. Scand J Work Environ Health 1987;13:118-23.

9 Heppleston AG. Silica, pneumoconiosis, and carcinoma of the lung. Am J Ind Med 1985;7:285-94.

10 Archer VE, Roscoe JR, Brown D. Is silica or radon daughters the important factor in the excess lung cancer among underground miners? In: Goldsmith DF, Winn DM, Shy CM, eds. Silica, silicosis and cancer: controversy in occupational medicine. (Cancer research monographs, vol 2.) New York: Praeger, 1986:375-84.

11 Davies JCA, Landau SP, Goldsmith C, Langton ME. Mesothelioma risk among gold miners in South Africa. $S$ Afr J Sci 1987;83:184-5.

12 Wiles FJ, Faure HM. Chronic obstructive lung disease in gold miners. In: Walton $\mathrm{WH}$, ed. Inhaled particles $I V$. London: Pergamon Press, 1977:727-35.

Accepted 10 July 1989 